\title{
PRESIÓN HÍDRICA EN AMBIENTES LACUSTRES DE ALTA MONTAÑA: ENTRE EL CAMBIO CLIMÁTICO Y EL DESARROLLO ENERGÉTICO. LAGUNA DEL LAJA, CHILE
}

\author{
HIDRIC RESOURCE PRESSURE IN HIGH MOUNTAIN LAKE ENVIRONMENTS: \\ BETWEEN CLIMATE CHANGE AND ENERGY DEVELOPMENT. \\ LAGUNA DEL LAJA, CHILE
}

Patricio Díaz Arellano*, Edilia Jaque Castillo* y Carolina G. Ojeda**

\begin{abstract}
Los ambientes lacustres de montaña son altamente sensibles a modificaciones climáticas y antrópicas, el lago Laja en Chile central presenta modificaciones severas en los últimos años, impactando toda su cuenca. Mediante el análisis diacrónico de imágenes satelitales multitemporales Landsat (1986-2016), con clasificación supervisada (ENVI) y evaluados los cambios (Idrisi Andes), buscamos definir los principales factores que explicarían los cambios en este sistema lacustre, mediante el análisis de las coberturas de suelo, la distribución de los derechos de agua y los datos climáticos. Se observa una reducción de precipitaciones de 1500-2000 mm a 970-780 mm anuales y un aumento sostenido de la temperatura entre 1,3-1,6 ${ }^{\circ} \mathrm{C}$, además se reconocieron fluctuaciones de la cobertura de superficie inundada del lago de 9.994,63 ha (1985) a 5.135,6 ha (2013), es decir, una reducción en el período de $48,6 \%$. Entonces el retroceso sistemático del lago Laja no se explica por las variaciones climáticas analizadas, lo que nos lleva a inferir que el causante externo principal de este proceso es la acción antrópica, expresada en la presión y competencia por el uso del recurso hídrico entre actores con desiguales relaciones de poder: centrales hidroeléctricas, pequeños-medianos agricultores, habitantes del sector y empresarios del turismo.
\end{abstract}

Palabras claves: Cambios de cobertura, sistemas lacustres de alta montaña, recursos hídricos, NDVI, cuenca del lago Laja.

Mountain lake environments are highly sensitive to climatic and anthropogenic changes, Lake Laja in central Chile has undergone severe modifications in recent years, impacting its entire basin. Through the diachronic analysis of multi-temporal satellite images Landsat (1986-2016) with supervised classification (ENVI) and evaluated the changes (Idrisi Andes). We define the main factors that would explain the changes in this lacustrine system through analysis of land cover, distribution of water rights and climate data. A reduction of rainfall of 1500-2000 $\mathrm{mm}$ is observed to 970-780 mm annually and a sustained increase of the temperature between 1.3-1.6 ${ }^{\circ} \mathrm{C}$., also was recognized fluctuations of the flooded surface cover of the lake of 9.994,63 $\mathrm{Ha}(1985)$ to 5.135,6 $\mathrm{Ha}$ (2013), i.e. a reduction in the period of $48.6 \%$. Then the systematic retreat of Lake Laja is not explained by the climatic variations analyzed, which leads us to infer that the main external cause of this process is the anthropic action, expressed in the pressure and competition for the use of the water resource between actors with unequal relations of power: hydropower plants, small-medium farmers, inhabitants of the sector and entrepreneurs of tourism.

Key words: Land Cover changes, high mountain lake systems, hydric resources, NDVI, Laja Lake Basin.

\section{Introducción}

Los ambientes de alta montaña son territorios poco favorables para el asentamiento humano. En particular se los considera como cordilleras o cordones montañosos a partir de los dos mil metros de altura (Zorrilla 2000) y poseen condiciones climáticas difíciles: las temperaturas mínimas en invierno son inferiores a $10{ }^{\circ} \mathrm{C}$ y las precipitaciones oscilan entre 1.200 y $1.500 \mathrm{~mm}$ anuales, casi siempre en forma de nieve en invierno (Dirección Meteorológica de
Chile 2016). El ser humano ha encontrado para estos territorios diversos usos como por ejemplo: el turismo (esquí), la protección natural mediante parques naturales, minería, y la generación de hidroelectricidad.

Estos paisajes de montaña son geosistemas que evolucionan a escalas geológicas que los seres humanos no alcanzan a percibir: Aparece de acuerdo a la mirada de quien lo observa, es decir, este modo de ser del paisaje sugiere que no siempre exista para todos y que su aparecer se manifieste solo para

\footnotetext{
* Universidad de Concepción. Concepción, Chile. Correos electrónicos: patriciodiaz@udec.cl; edjaque@udec.cl

** Universidad Católica de la Santísima Concepción. Concepción, Chile. Correo electrónico: carojedaleal@gmail.com (autor correspondiente).
} 
algunos a quienes se les devela desde su sustrato geográfico (Galleguillos y Ojeda Leal 2016).

Las dinámicas físicas de estos paisajes están influenciadas tanto por las paleocondiciones al interior de la cuenca de drenaje (Syvitski 2003) como por las perturbaciones de los seres humanos durante el Antropoceno (Brondizio et al. 2016), es decir, durante la era en que la civilización humana podría afectar de manera fundamental el clima planetario ${ }^{1}$ con consecuencias a posteriori que aún no son completamente conocidas (Postigo et al. 2013). Estas alteraciones comprometen los servicios de los ecosistemas de agua dulce, generando erosión que reduce la productividad del suelo cercano a sus cauces e impulsa cambios ecológicos en los ecosistemas acuáticos a lo largo de toda la cuenca (Restrepo et al. 2015).

Frente a estos fenómenos, Naciones Unidas ha generado políticas de protección de estos paisajes como lo son las declaratorias de Patrimonio de la Humanidad o Reserva de la Biósfera buscando limitar su destrucción o alteración (ONU 2014). Las transformaciones más representativas que se han estudiado para estos paisajes de alta montaña, según García (2011), son los siguientes:

- Desplazamiento altitudinal de muchos animales y plantas. Reducción de la superficie de los pisos ecológicos situados en las zonas más altas.

- Modificación de la intensidad y consecuencias de diversos procesos geomorfológicos como aludes o remoción en masa.

- Desaparición de nieve-glaciares y la reducción de los caudales disponibles en primavera/verano en las cuencas hidrográficas de las que son cabecera.

Estos paisajes de montaña son particularmente sensibles a las alteraciones, ya que son el origen de los cauces fluviales y muchas veces albergan en sus faldeos actores que usan diversos lenguajes de valoración para los recursos (Martínez-Alier 2004), originando múltiples conflictos (Gleick 1995) entre el recurso agua y sus usuarios.

El estudio de Becerra et al. (2006), orienta definiciones en torno a lo que significa el término conflicto, el que se traduce en una disputa que posee ciertas características, como a) se manifiestan mediante acciones observables $y, b$ ) surgen primordialmente a causa de la escasez de un recurso en disputa (Gleick 1998). Este término se ha asociado hasta crear una nueva categoría conocida como conflicto socioambiental, es decir, las disputas entre diversos actores -personas naturales, organizaciones, empresas públicas y privadas, y el Estado-, manifestadas públicamente y que expresan divergencias de opiniones, posiciones, intereses y planteamientos de demandas por la afectación (o potencial afectación) de derechos humanos, derivada del acceso y uso de los recursos naturales, así como por los impactos ambientales de las actividades económicas (INDH 2012: 246).

Es precisamente esta disputa la que genera conflictos que se consideran como origen de los procesos enfocados en la presión por el recurso hídrico -o presión hídrica-, es decir, las fuerzas que ejercen los diversos actores o usuarios para su predominancia en el aprovechamiento o conservación del recurso y cuya acción en el conflicto va a depender de sus recursos económicos, políticos o mediáticos (Bustos et al 2015; Astorga et al. 2015).

En Chile se han documentado diversos conflictos en materia de recursos hídricos de montaña. Así, en la Zona Norte, el conflicto del agua se asocia con la explotación minera y sus altos requerimientos, principalmente en faenas de oro y cobre (Prieto 2017; Yáñez y Molina 2011). En la zona centro los conflictos se acentúan por la diversidad de actividades que se sustentan en el recurso hídrico como el consumo de las napas subterráneas por plantaciones forestales, la contaminación de ríos por celulosa o desechos y la sobreexplotación hidroeléctrica (Obregón 2013; Budds 2012). En la Zona Sur suceden conflictos en materia de generación de electricidad y la falta de agua potable en sectores rurales o mapuches (Larraín y Poo 2010; Cabello Cádiz y Torres 2015; Seoane, Taddei y Algranati 2006).

Todos los anteriores conflictos en torno a los recursos se han hecho más frecuentes a medida que nuestro planeta se enfrenta a un proceso de cambio climático. A pesar de tener características únicas posee una extensión global, impactos en el largo plazo en el clima tal como lo conocemos, alteraciones de las interacciones complejas entre procesos naturales -fenómenos ecológicos/climáticos- y modificaciones de los medios de producción insertos en una economía de libre mercado (Martínez y Osnaya 2004).

Este tipo de economía ha pasado a depender en gran medida de los combustibles fósiles y de la hidroelectricidad alimentando el desbalance de los 
procesos ecológicos que sostienen el cambio climático (Speranza et al. 2013). Muchos países -incluido Chile- durante las últimas décadas han transitado desde el uso exclusivo de estos combustibles hacia una matriz energética mixta incluyendo energías renovables -eólica, solar, geotérmica, mareomotriz y biocombustibles-, todas ellas insertas en estrategias conocidas como políticas de desarrollo energético (MMA 2014; CEPAL 2012).

La problemática a investigar para la cuenca del lago Laja (Chile) se enmarca en la sistemática reducción del espejo de agua, situación que ha sido explicada hasta ahora como una respuesta frente al cambio climático, es decir, asociada a la reducción de precipitaciones, desaparición de la nieve y reducción de glaciares. Se propone indagar con un enfoque geográfico cuantitativo otras posibles causas de carácter antropogénico analizando los cambios temporales en las coberturas de suelo de la cuenca superior del Laja (1986-2016) -con énfasis en la cobertura del espejo de agua-y el aprovechamiento que hacen de sus aguas sus usuarios legales, para responder a la pregunta de investigación: ¿Existen otras causas que influyan en la reducción del espejo de agua, además de los factores climáticos?

La hipótesis que se pretende indagar consiste en que: es posible de identificar otros factores que influyen en la reducción del espejo de agua, y estos se asocian con el uso que hacen los seres humanos de estos recursos en un contexto global de escasez hídrica.

\section{Materiales y Métodos}

\section{Área de estudio}

La cuenca del Laja se sitúa entre los $36^{\circ} 50^{\prime}-37^{\circ}$ $40^{\prime} \mathrm{S}$ y $\operatorname{los} 71^{\circ} 7^{\prime}-72^{\circ} 45^{\prime} \mathrm{W}$, en el centro-sur de Chile (Figura 2). Esta posee una superficie aproximada de 97.000 ha, emplazando su cabecera en la cordillera Andina entre los complejos volcánicos de Antuco-Sierra Velluda -3.585 m- y Nevados de Chillán -3.212 m- (Moreno y Varela 1987; SERNAGEOMIN, Niemeyer y Muñoz 1983). El río Laja es su curso principal cuyo nacimiento se origina en el lago Laja a 1.368 m.s.n.m., transcurriendo hacia el Oeste por la depresión central y confluyendo en el río Biobío. Tiene régimen mixto (nivopluvial) y su caudal medio anual es de 170 $\mathrm{m}^{3}$ a la salida de la cordillera Andina (DGA 2014; Niemeyer y Cereceda 1984).
Los principales sustentos económicos del sistema social de la cuenca del río Laja son producto de las actividades forestales (39\%) -pino radiata e insigne y eucalipto-y agrícolas (34\%) -trigo, maíz, papas, remolacha, raps, maravilla, viñedos, cerezos, manzanos, perales-, cuya mayor concentración está en el flanco oriental de la cordillera de la costa y en la parte occidental de la depresión intermedia (González, González y Mardones 2003).

Otros usos como el atractivo turismo nacional, pesca y ecoturismo se concentran en el Salto del Laja, localizado a $110 \mathrm{~km}$ río abajo. Los principales núcleos urbanos que se ubican en la cuenca alrededor del río Laja son las comunas de Antuco (3.908 hab), Cabrero (21.492 hab), Laja (22.404 hab), Los Ángeles (186.671 hab), Tucapel (13.497 hab), Yungay (9.288 hab), San Rosendo (3.757 hab), Quilleco (10.033 hab) y Yumbel (20.498 hab) (Censo 2002).

El río Laja es regulado en el curso superior naturalmente por el lago Laja y artificialmente por el uso hidroeléctrico. Según Mardones y Jaque (1991), el lago tiene $33 \mathrm{~km}$ de longitud y ancho de $3 \mathrm{~km}$, una profundidad media de $75 \mathrm{~m}$ respecto de la cota de $1.368 \mathrm{~m}$ y una superficie aproximada de $851 \mathrm{~km}^{2}$. El caudal medio de la hoya afluente al lago es de $66,6 \mathrm{~m}^{3} / \mathrm{s}$ y el caudal medio efluente de $60 \mathrm{~m}^{3} / \mathrm{s}$. La descarga del lago se realiza por la bocatoma de la central hidroeléctrica El Toro con un caudal medio anual de $39,6 \mathrm{~m}^{3} / \mathrm{s}$, además, del drenaje subterráneo en su frente producto de la naturaleza volcánica del suelo, con un caudal medio anual de $27 \mathrm{~m}^{3} / \mathrm{s}$. Estas filtraciones se concentran en los lugares conocidos como "Ojos del Laja" localizados $3 \mathrm{~km}$ al Oeste del frente lacustre (Mardones y Jaque 1991).

\section{Métodos y técnicas de investigación}

En primer lugar se evaluó la dinámica de las coberturas de suelo de la cuenca del Laja, la que posee una superficie aproximada de 97.000 ha -correspondiente a la zona de estudio-, mediante el análisis de imágenes satelitales multitemporales (1986-1990, 1999-2012 y 2013-2016) utilizando los software ENVI 5.0 y ArcGis 10.2 (Chuvieco 1998) (Viloria et al. 2016). Para generar el cálculo de estos se utilizó la siguiente fórmula en cada banda según el año en que fueron extraídas -Landsat 7 : Bandas 4-3 y para Landsat 8: Bandas 5-4- (Pineda et al. 2016): 


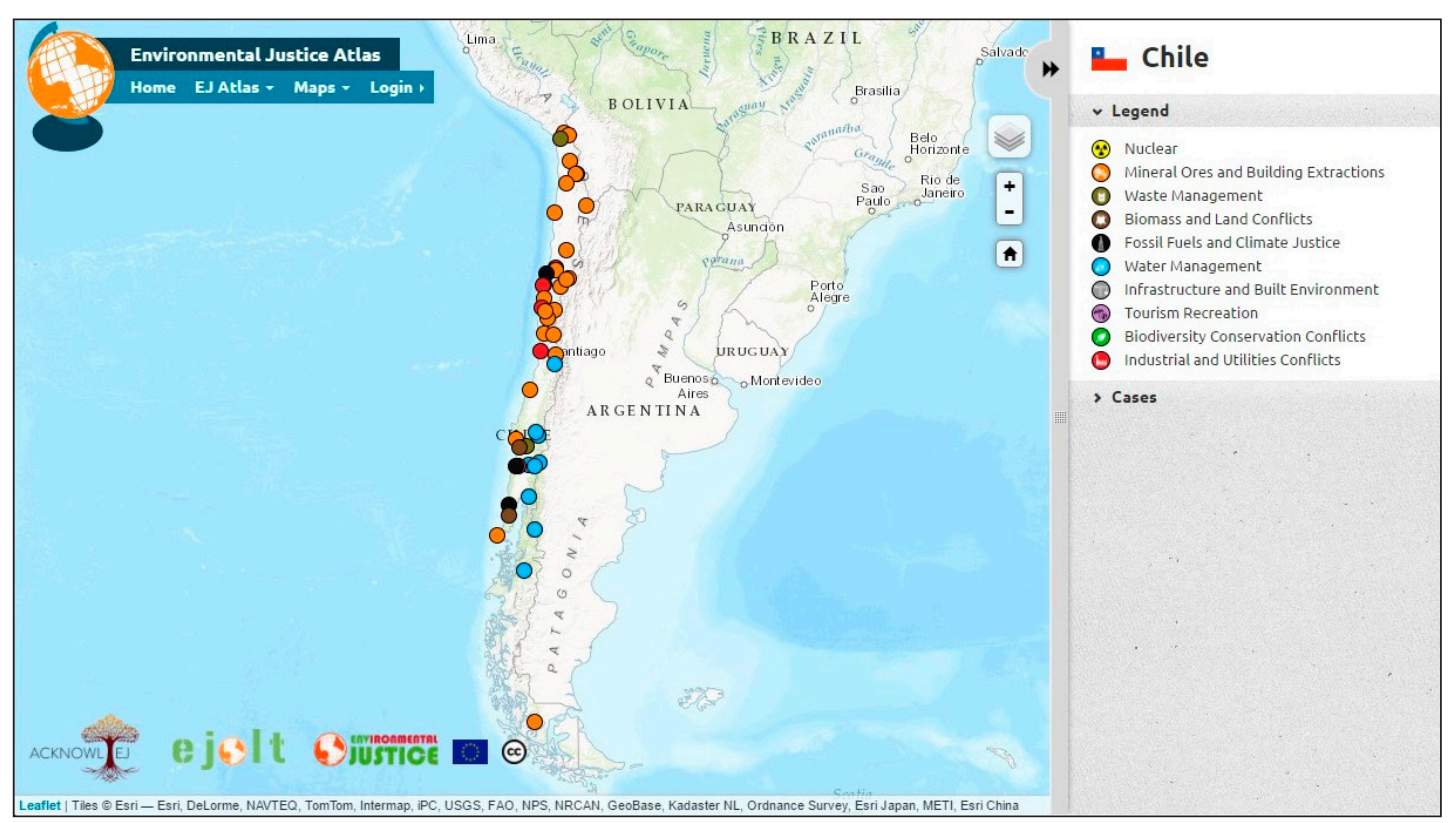

Figura 1. Mapa de algunos conflictos ambientales en Chile. Fuente: Environmental Justice Atlas, 2017.

$$
N D V I=(\rho N I R-\rho I R) /(\rho N I R+\rho)
$$

Donde: NIR: reflectancia en la banda del infrarrojo cercano; $R$ : reflectancia en la banda roja.

En segundo lugar se calculó el NDVI (Boone et al. 2007), que mide la relación entre la energía absorbida y la emitida por los objetos terrestres. Aplicado a las comunidades de plantas, el índice arroja valores de intensidad del verdor de la zona ( -1 a +1) (Tovar 2012:40) (Maselli 2004, Krishnaswamy et al. 2009). La vegetación es un excelente indicador morfológico del comportamiento hídrico de cuerpos de agua y sostenibilidad en general (García y Guerrero 2006). Para detectar los cambios ocurridos en el cuerpo lacustre que tiene una superficie aproximada de $851 \mathrm{~km}^{2}$ se realizó el análisis comparativo de los valores de NDVI de las imágenes (Pineda et al. 2016) utilizando la ecuación:

$$
\Delta \rho=N D V I E-N D V I R
$$

Donde: $\Delta \rho$ : diferencia de NDVI para cada pixel entre las imágenes $E$ y $R, N D V I E$ : NDVI de cada pixel de la imagen del año a evaluar, y NDVIR: NDVI de cada pixel de la imagen del año de referencia.

A pesar de la exactitud del índice NDVI para el análisis sugerido es preciso constatar en la validación en terreno de forma visual y real las clasificaciones identificadas en las imágenes satelitales (Boone et al. 2007), correspondiendo a dos tipos: la vegetación vigorosa recibe menos reflexión por parte del suelo al estar concentrada y ser absorbida por la clorofila existente entre estas zonas, lo contrario ocurre con la vegetación dispersa.

En la temporada de invierno la capa de nieve que cubría el sector impidió el desarrollo de vegetación apreciable, encontrándose sectores de suelos desnudos en menor cantidad en comparación con temporadas estivales. Esta diferencia es notoria en enero-febrero, ante el aumento de las temperaturas y la disminución de las precipitaciones (Figura 3).

En tercer lugar se analizaron las temperaturas y precipitaciones históricas en la cuenca del Laja con datos de la Dirección General de Aguas ${ }^{2}$ (DGA) en las estaciones meteorológicas más cercanas (Caracol y Diguillín) que continúan funcionado durante el período estudiado (1985-2016). Complementariamente se realizaron dos campañas de terreno en septiembre-diciembre 2014 para la constatación de los cambios y la toma de fotografías del área de estudio.

Finalmente, los derechos de agua, única información pública que permite conocer el uso que se le da al recurso hídrico por parte de los habitantes y 

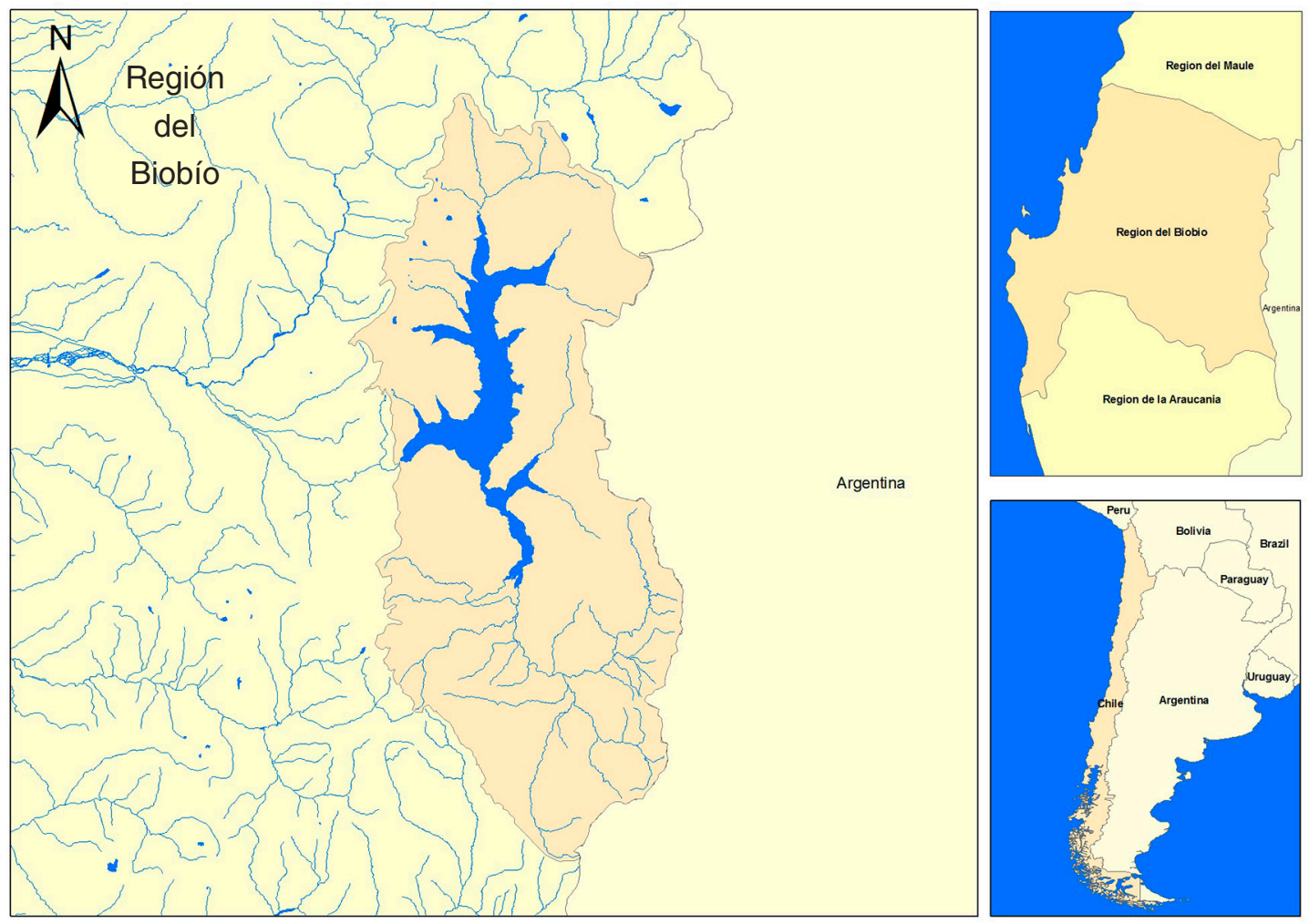

Figura 2. Área de estudio: cuenca del lago Laja (Chile). Fuente: Elaboración propia.

las empresas hidroeléctricas del sector, fueron espacializados con ArcGis 10.2 generando un mapa que nos permite inferir la influencia de las actividades económicas, en el estado actual del espejo de agua y su curso medio e inferior (Figura 4).

\section{Resultados}

\section{Dinámica de las coberturas de suelo de la cuenca superior del lago Laja}

El análisis de las imágenes satelitales entre 1986 y 2014 en la cabecera de la cuenca del Laja muestra que en este período de 38 años las coberturas que más se han visto modificadas son: el espejo de agua (superficie inundada), arenas volcánicas y nieve. Esta última va en directa relación con la estacionalidad al momento de realizar la clasificación de uso de suelo (verano). El lago Laja alcanzaba según los reportes de la época en 1986 una superficie de 9.130,5 ha, lo que correspondía a 9,42\% de la cabecera de la cuenca del Laja (área de estudio). Para el 2014 el espejo de agua presentaba una superficie de 6.793,7 ha, es decir 7,2\% de la cabecera de la cuenca. Hay una disminución de 2.336,8 ha de espejo de agua, $25,6 \%$ de disminución de la superficie inundada en 38 años.

Como se muestra en las figuras 5 a y 5 b, la cobertura de suelos desnudos posee un promedio anual cercano a las 50.000 ha de forma estacional, ya que estas descienden en invierno ante la mayor cantidad de superficie nival. La cobertura de arenas volcánicas de 1986 mostraba una superficie de 10.163 ha que representaban $10,49 \%$ de la cabecera de la cuenca. En 2014 esta misma cobertura alcanzaba 11.139 ha con $11,49 \%$, aproximadamente 1.000 ha mayor a la de 1986.

Los bosques de renovales y nativos que hay en esta cabecera presentan para el año 1986 una superficie aproximada de 18.045 ha, lo que equivale a $18,62 \%$ de la superficie de la cabecera de la cuenca, en tanto para el 2014 poseían una superficie aproximada de $8.009,1$ ha, lo que representa $8,26 \%$ de la superficie total de la cabecera de la cuenca en estudio con una reducción del $65,7 \%$ (Figura 6). 


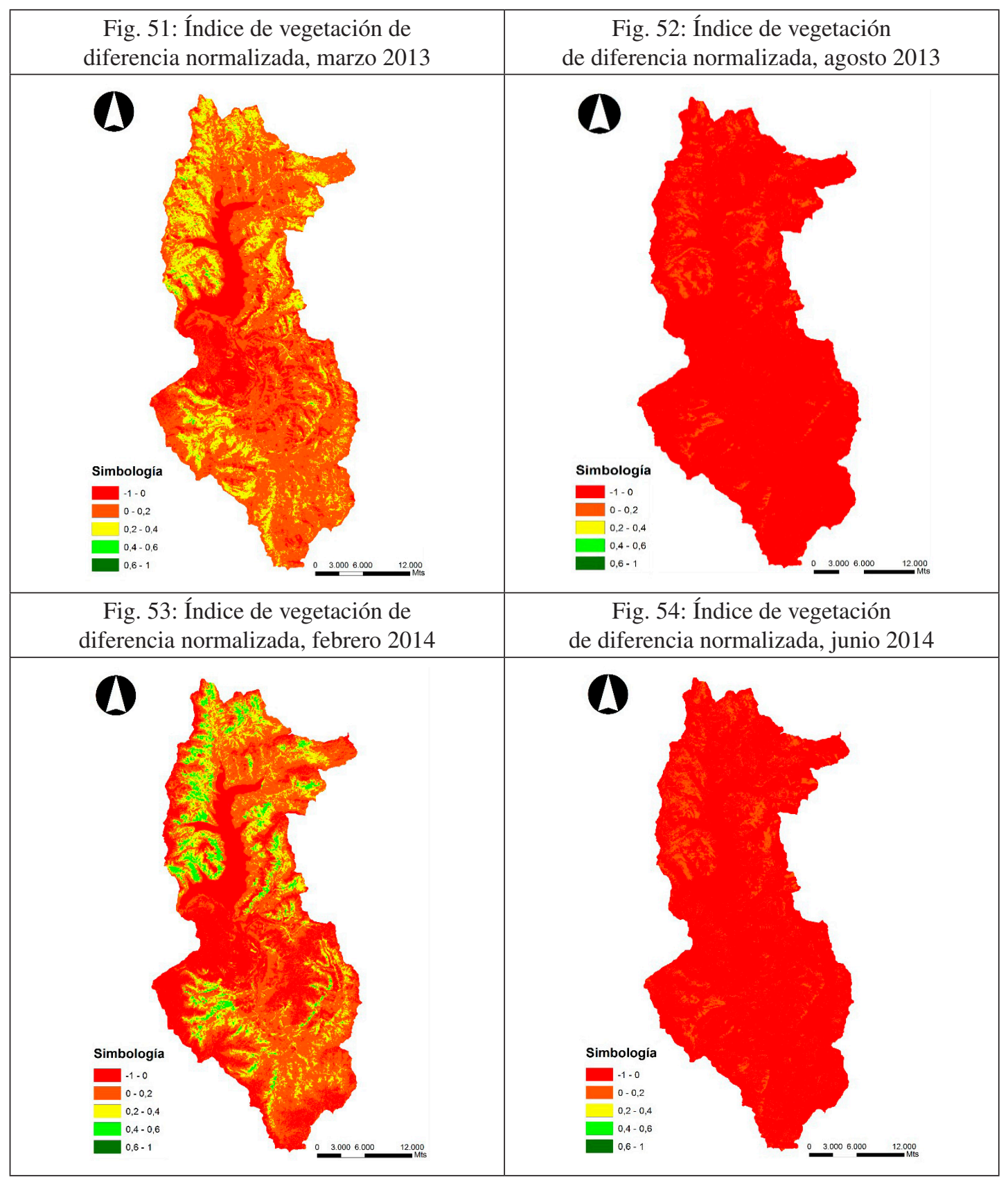

Figura 3. Análisis NDVI para el Lago Laja (2013-2014). Fuente: Elaboración propia.

La cobertura correspondiente a rocas volcánicas alcanzaba una superficie aproximada de 10.163 ha para 1986, es decir, 10,49\% en relación con el total de superficie de la cabecera de cuenca; aumentando en el 2015 a 11.139 ha, lo que equivale a un aumento de $9,1 \%$. Otra de las coberturas que presentaron cambios significativos fue la cobertura de nieve en 1986, la que alcanzaba una superficie de
2.721 ha en verano y aumentó a una superficie de $7.874,5$ ha (2014). Estas fluctuaciones se relacionan directamente con la variabilidad estacional de los fenómenos climáticos de alta montaña.

Sin embargo, existieron dos atípicos momentos en el periodo estudiado: uno en 1999 cuando el espejo de agua alcanzó a 5.666 ha, con 5,85\% de la superficie de la cabecera de la cuenca y el año 


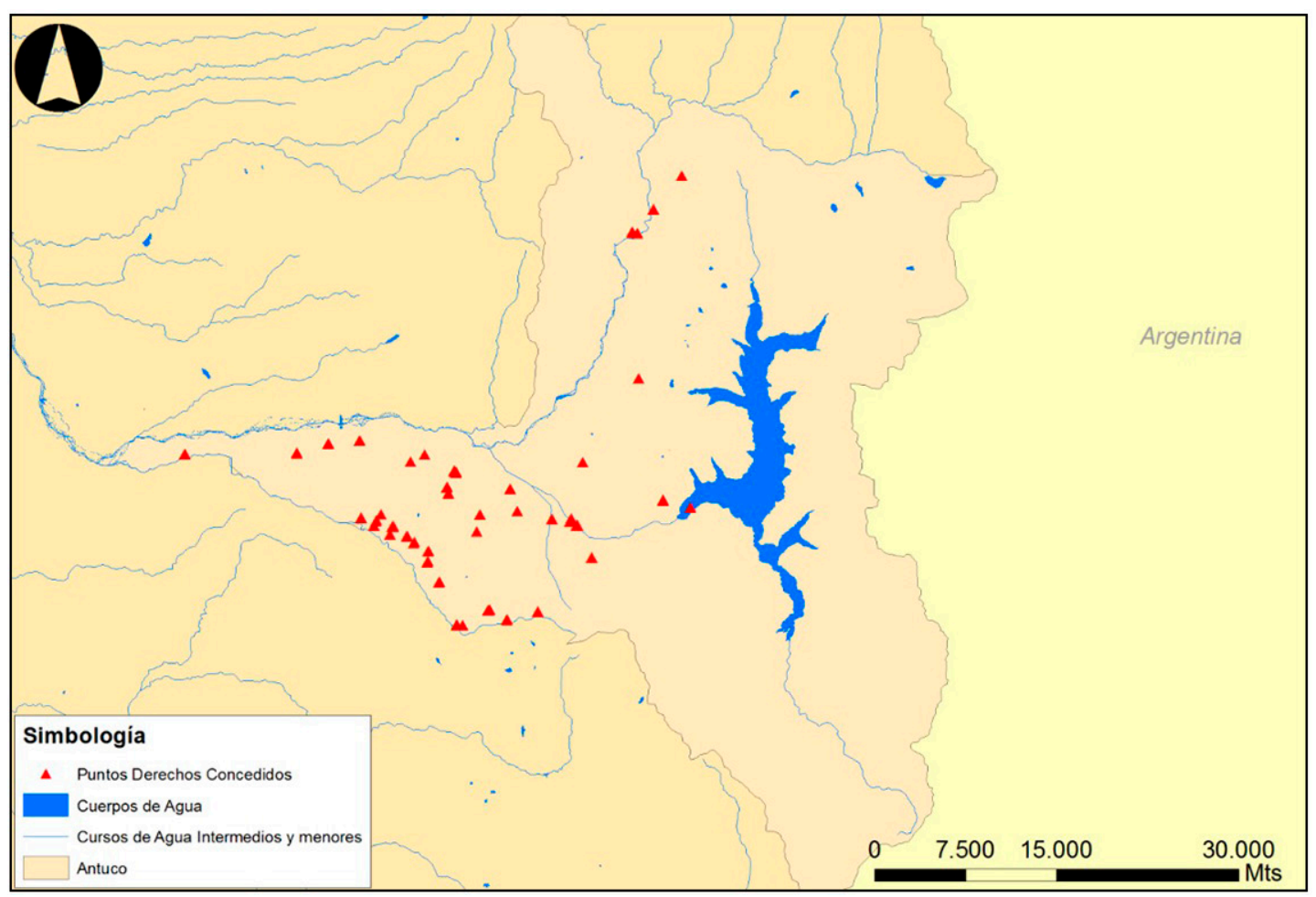

Figura 4. Mapa de derechos de aprovechamiento de agua para la comuna de Antuco. Fuente: Elaboración propia en base a datos DGA.

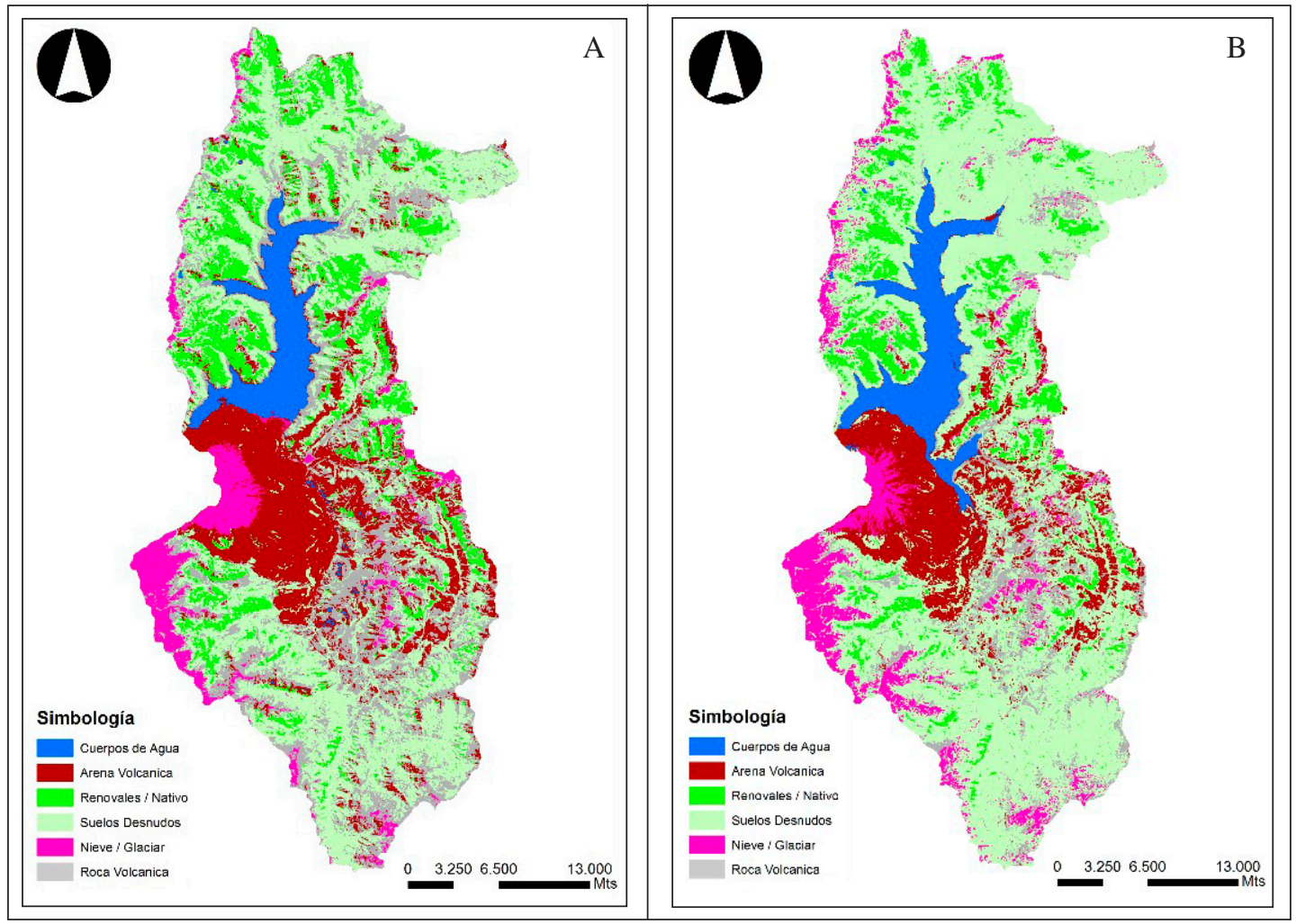

Figuras 5a-5b. Análisis de cambio de cobertura de suelo (1986-2014) cuenca Lago Laja. Fuente: Elaboración propia. 


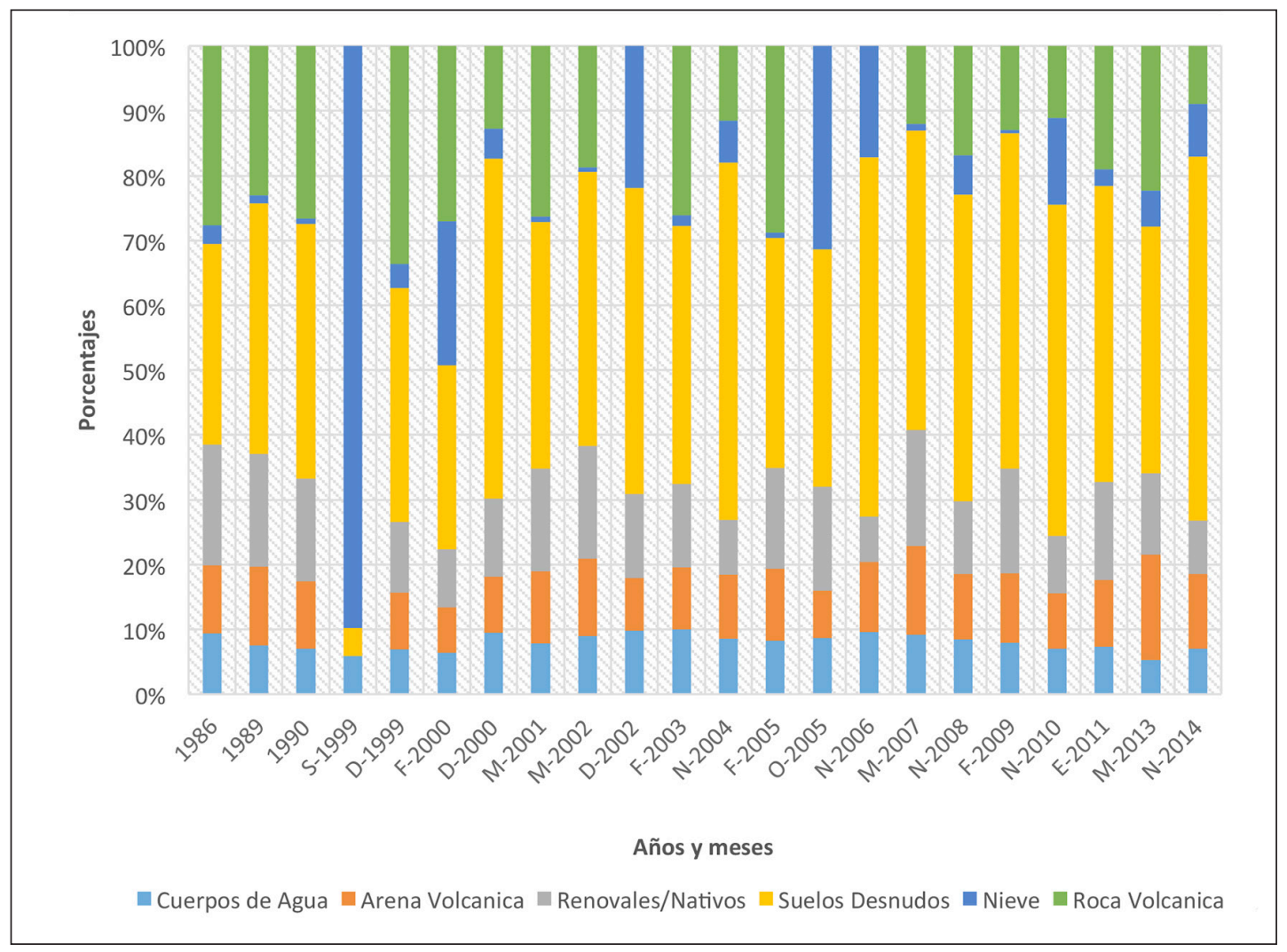

Figura 6. Variaciones de las coberturas de suelo (1986-2014) para la cuenca del lago Laja. Fuente: Elaboración propia.

2013 en que alcanzó una superficie de 5.135,6 ha, es decir, 5,3\% de la cabecera.

Las dimensiones de cuál puede ser el significado del anómalo año 1999 se estudian desde diferentes sectores, pero la explicación más recurrente es la grave sequía y la venta del agua equivalente a 316 GWh destinada a riego de parte del MOP (Díaz, Galetovic y Soto 2000). Según Bernstein (1999), el año hidrológico que va desde abril de 1998 a marzo de 1999 fue más seco que el de 1968-69 (considerados los más secos del siglo y bases del cálculo de precios energéticos) en términos de los caudales afluentes a las centrales del SIC. Por ejemplo, durante el año hidrológico1998-99 los afluentes del lago Laja conducían solo $65 \%$ de lo normal y 35\% menos que en 1968-69 (Tabla 1).

La sequía de 1999 dio lugar a una menor acumulación de nieve en la cordillera, lo que hizo prever una menor cantidad de agua disponible durante los deshielos que debían ocurrir entre octubre y marzo. De esta forma, ya en agosto de 1998 era posible anticipar serios problemas de abastecimiento hasta
Tabla 1. Afluentes de embalses lago Laja (año normal $=100)$.

\begin{tabular}{cccc}
\hline \multirow{2}{*}{$\begin{array}{c}\text { Año hidrológico } \\
\text { completo }\end{array}$} & Normal & $1968-9$ & $1998-99$ \\
\cline { 2 - 4 } & 100 & 52 & 34 \\
\hline Noviembre a marzo & 100 & 58 & 29 \\
\hline
\end{tabular}

Fuente: Adaptado de Díaz, Galetovic y Soto, 2000.

mediados de 1999, sin embargo no se hizo, lo que provocó una de las mayores crisis energéticas y un periodo de racionamientos eléctricos forzados por medio del Decreto 287 (BCN 1999).

Estas variaciones en superficie inundada mostradas en las imágenes satelitales se aprecian también correlacionadas con los niveles de cota para el mismo período (Figura 7) muestran que los niveles máximos alcanzados fueron hace cerca de tres décadas, mientras que los mínimos, de forma constante, se han ido acrecentando desde fines de la década de los 90 y manteniendo niveles bajos históricos en los últimos dos años. 


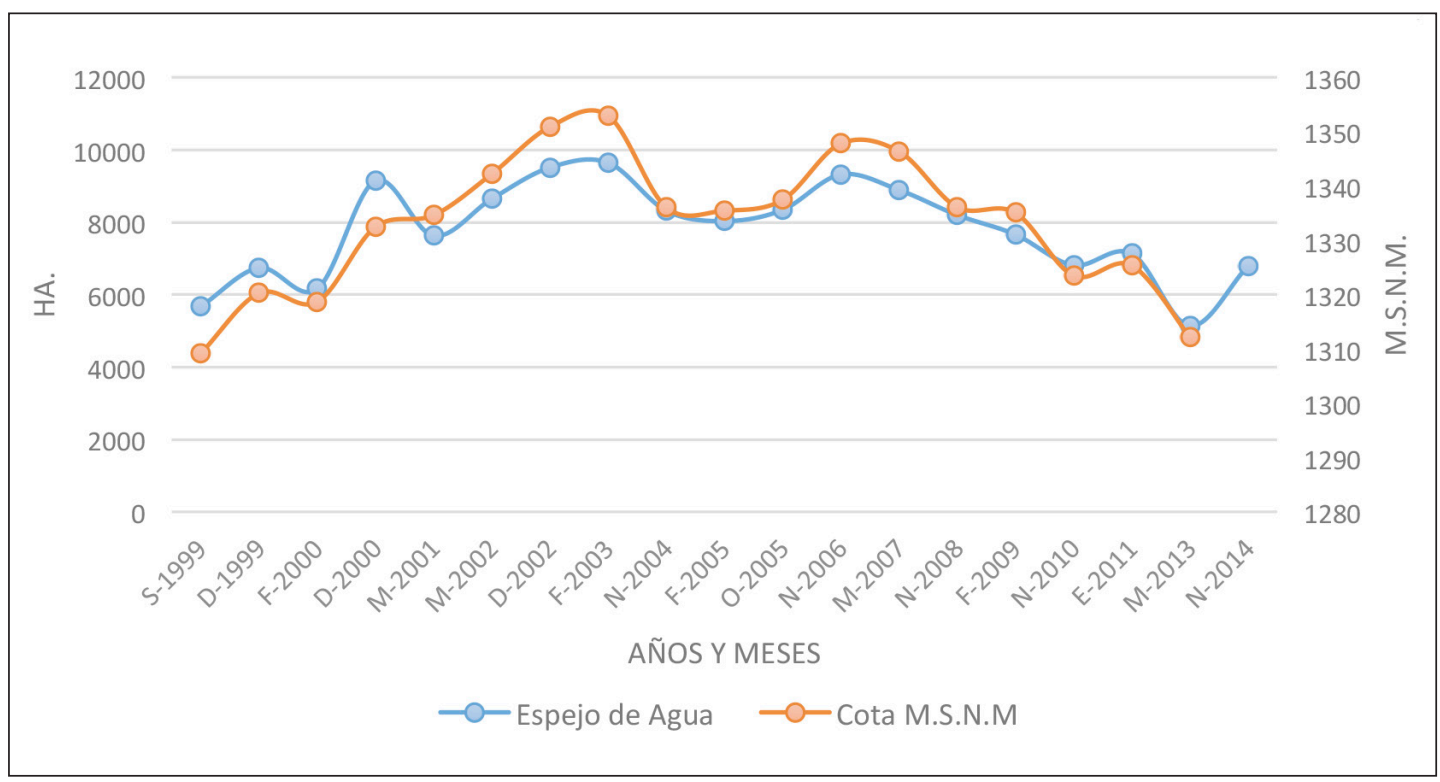

Figura 7. Cotas (m.s.n.m.) del espejo de agua del lago Laja (1986-2014). Fuente: Elaboración propia en base a datos DGA.

Estudios anteriores como el detallado estudio de Mardones y Vargas (2005:95) ayudan a comprender la historia anterior de los niveles de cota del lago Laja comenzando en 1941-1958 cuando la cota promedio del lago fue de $1.363,7 \mathrm{~m}$, lo que ellos llaman el "estado natural del lago". Durante 1958-1972, esta disminuyó a 1.345,5 m, lo que significó una disminución del espejo de agua de aproximadamente $18 \mathrm{~m}$; efecto que coincide con el inicio de las operaciones del Túnel de Vaciado de las centrales hidroeléctricas.

\section{Análisis de indicadores climáticos en estaciones meteorológicas cercanas}

Las estaciones meteorológicas Digüillín y Caracol (Figura 8), ubicadas en la provincia del Nuble, son las únicas cercanas y confiables para medir las temperaturas, ya que otras estaciones vistas en la región no cumplían con una continuidad en el flujo de datos o no poseían suficiente antigüedad. A estos datos se les aplicó un valor de gradiente térmico vertical de $0.65^{\circ} \mathrm{C}$ por cada $100 \mathrm{~m}$, profusamente descrito por la literatura como valor estándar para el descenso de temperatura en altura -para este caso 1.700 m.s.n.m- (Martínez del Castillo et al. 2010).

En materia de precipitaciones se trabajaron dos estaciones, la de Abanico -perteneciente a ENDESA-y la Estación Tucapel, ambas registrando datos desde 1976-2013.
El análisis realizado permite observar en la estación Abanico una leve tendencia al descenso de precipitaciones en el período 1964-1999 (DGA 2014b), considerando que las precipitaciones para un año normal están por encima de $2.000 \mathrm{~mm}$, a excepción de lo ocurrido en 1972, el que obtuvo un promedio de $3.000 \mathrm{~mm}$ anuales (Figura 9). El momento crítico según este registro fue 1998, con lluvias que no alcanzaron los $1.000 \mathrm{~mm}$ a consecuencia del fenómeno climático de El Niño detectado ese año (1998-1999) (DGA 2014c). La Estación Tucapel (DGA 2014d) mostró una tendencia marcada al descenso, presentando momentos críticos durante diversos años: en 1998 (inferior a los $800 \mathrm{~mm}$ en el año), en 2007 (con un poco más de $990 \mathrm{~mm}$ ) y 2013 (con un poco más de $980 \mathrm{~mm}$ ).

\section{Implicancia de la entrega de concesiones de derechos de agua en la cuenca del lago Laja}

El estudio de la CEPAL acerca de la disponibilidad futura de los recursos hídricos frente a escenarios de cambio climático en Chile, muestra que la proyección de variación en los caudales medios anuales en la cuenca del Laja hacia fines del siglo XXI corresponde a una disminución del orden de $40 \%$ y se crea un escenario complejo al 2100 existiendo una menor disponibilidad de agua precipitada para el escurrimiento superficial y el volumen de nieve disponible para el deshielo 


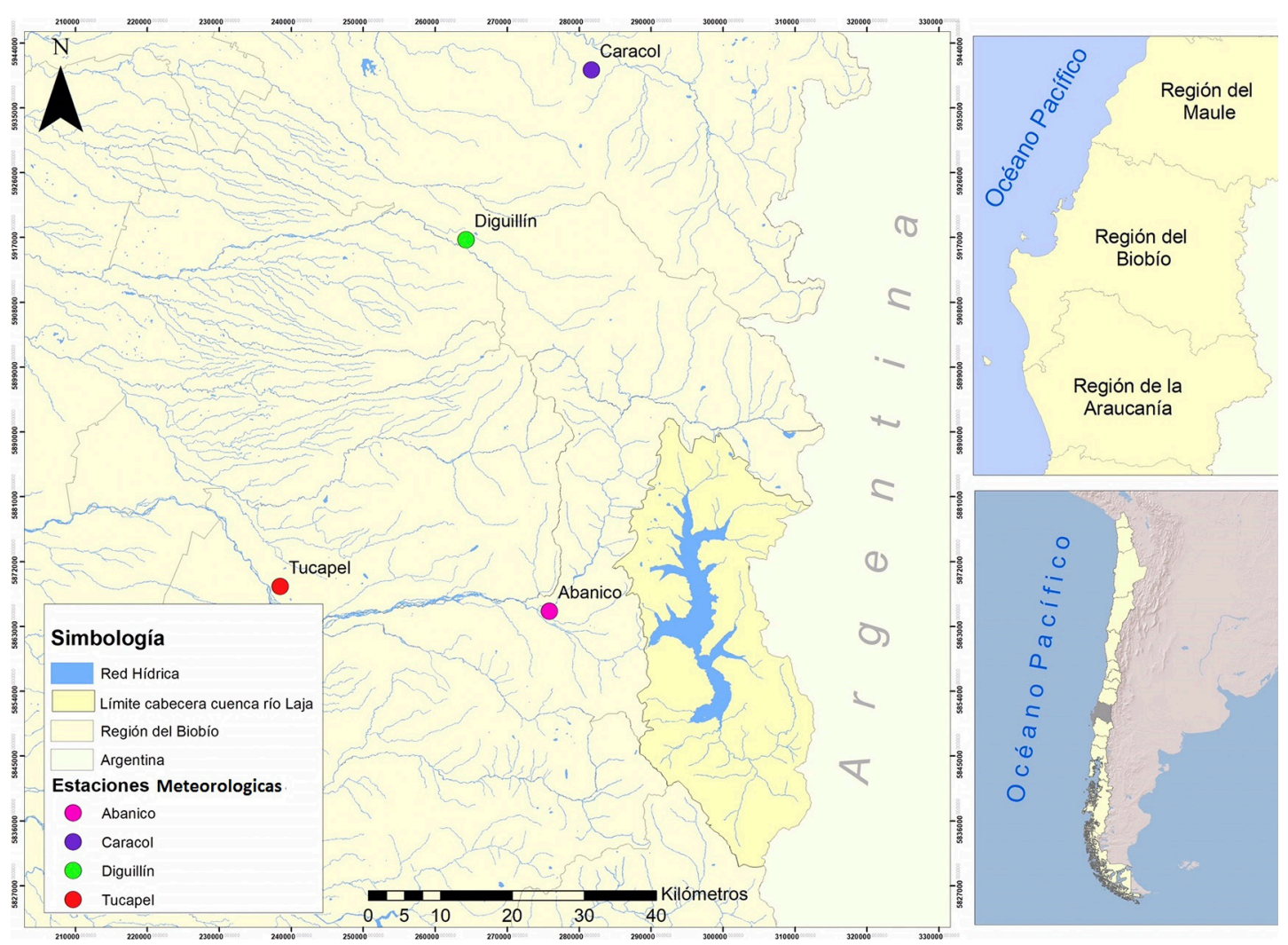

Figura 8. Ubicación de las estaciones meteorológicas en el área de estudio. Fuente: Elaboración propia en base a datos DGA.

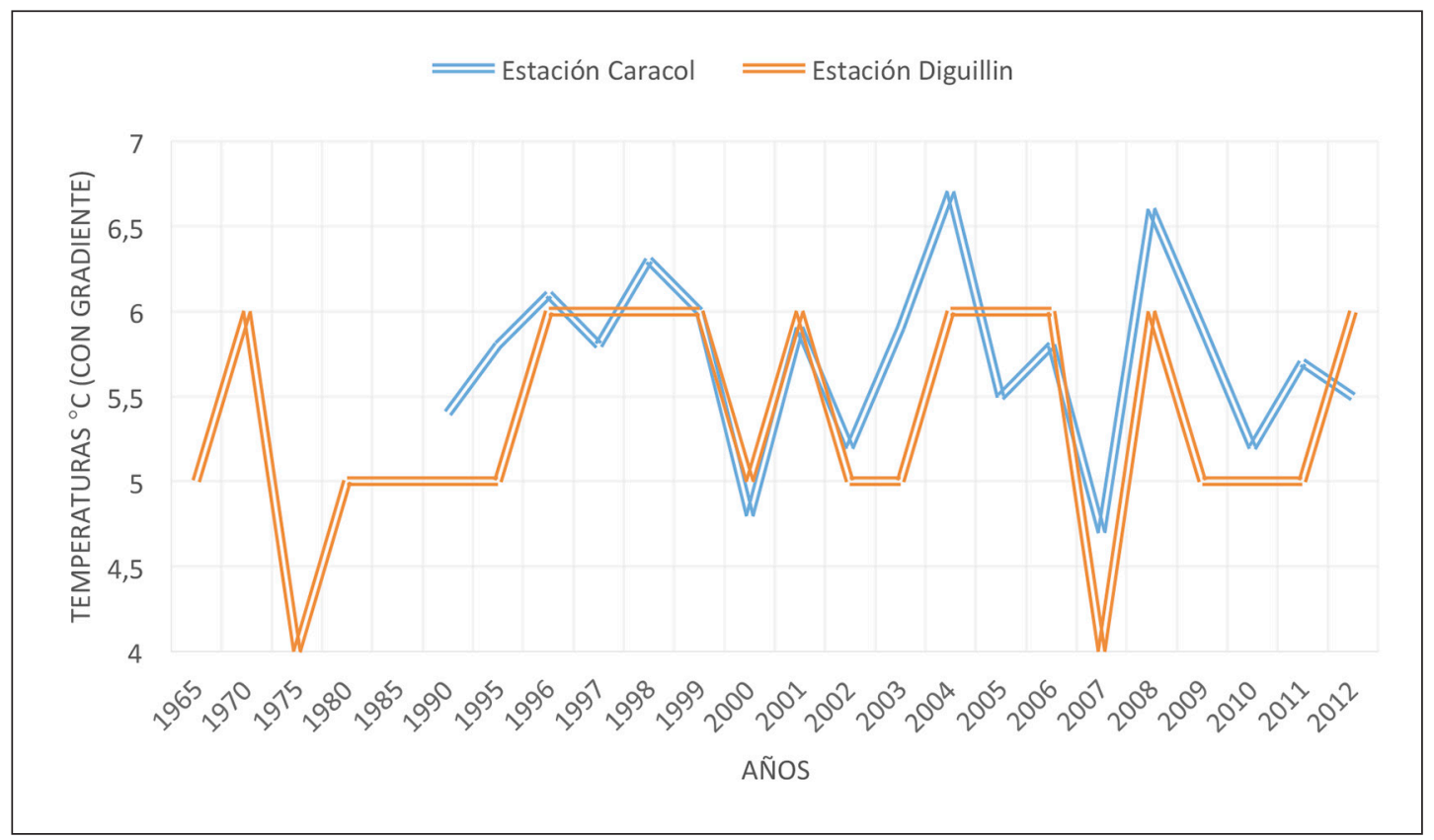

Figura 9. Temperaturas promedio anuales $\left({ }^{\circ} \mathrm{C}\right)$ para las estaciones Diguillín y Caracol (1965-2012). Fuente: Elaboración propia en base a datos DGA. 
(CEPAL 2012:90). En la realidad del territorio, es muy difícil lograr un real compromiso con la explotación sustentable de los recursos hídricos si estos se encuentran desbalanceados en cuanto a las dinámicas de poder de los diversos actores involucrados (Prieto y Bauer 2012).

Este escenario tan complejo plantea dudas respecto de la implicancia de una correcta gestión hídrica en Chile, pues aunque se intentó hacer un esfuerzo desde el sector público 3 (MOP 2011), este se ha mostrado insuficiente debido a la dispersión de funciones de los entes públicos y al modelo económico del libre mercado, el que supone que la eficiencia del uso del agua aumenta si este bien asume el valor y el precio real (Saavedra Brofman 2008). De acuerdo con Blanco Vergara (2010), las principales instituciones del Estado con funciones, competencias y atribuciones en la planificación de recursos hídricos corresponden a:
a) Ministerio de Obras Públicas (MOP).
b) Comisión Nacional de Riego (CNR).
c) Ministerio de Agricultura (MINAGRI).
d) Ministerio del Medio Ambiente (MMA).
e) Ministerio de Salud (MINSAL).
f) Ministerio de Bienes Nacionales (MBN).
g) Dirección General de Aguas (DGA).
h) Ministerio de Energía (ME).

Desde la legislación existente, se establece que los derechos de agua consisten en la entrega del derecho real de aprovechamiento que recae en aguas de dominio público, que consiste en el uso y disposición de ellas -en beneficio particular- con los requisitos y en conformidad a las disposiciones establecidas tanto en la Constitución como en el Código de Aguas (Peña 2004). El derecho consuntivo se refiere al derecho de consumo de aguas, sin que puedan reutilizarse superficialmente-riego, minería, industria y uso doméstico-. Por su parte, los derechos no consuntivos se refieren a aquellos que se solicitan para utilizar el agua sin consumirla, como es el caso de los proyectos hidroeléctricos (Larraín 2006).

La distribución espacial de los derechos de agua tanto de carácter subterráneo como superficiales concedidos en la región del Biobío desde 1915 al 2014 predominan en los sectores de la depresión intermedia (extracción superficial) y cordillera costera (extracción subterránea) (DGA 2014).

De 105 derechos entregados el año 2014 (Tabla 2), los actores predominantes son la empresa española Endesa con el uso para energía hidroeléctrica $(9 \%)$ y el riego $(10 \%)$, mientras que para el uso doméstico abarca el 6\%, dejando en los últimos lugares al uso industrial y otros usos sin datos (78\%) (DGA 2014).

Tabla 2. Derechos de aprovechamiento de agua en la comuna de Antuco,Chile.

\begin{tabular}{lr}
\hline Usos & $\%$ \\
\hline Bebida/uso doméstico/saneamiento & 6 \\
Energía hidroeléctrica & 9 \\
Otros usos & 1 \\
Riego & 10 \\
Uso industrial & 1 \\
Sin datos & 78 \\
Total & 100 \\
\hline
\end{tabular}

Fuente: DGA.

Esto se da considerando que el volumen útil para la generación de hidroelectricidad está almacenado entre las cotas 1.310 y 1.368 m.s.n.m. - en casos extremos, se permite su uso bajo la cota 1.310 m.s.n.m.- (Figura 10).

Bauer (2002) indica que no presentan información concerniente a la cantidad extraída de agua en $\mathrm{m}^{3}$ ni tampoco han sido regularizados respecto del consumo según los diferentes métodos de extracción, lo que abre la puerta a la incertidumbre del estado real del lago Laja (Bauer 2009), ya que está sujeto a un uso múltiple sin una planificación integrada a nivel de cuenca (Mardones y Vargas 2005).

Por sus características estructurales, la industria hidroeléctrica presente allí incurre en el mayor consumo efectivo de agua (9\%), abarcando desde la salida del lago hasta $9 \mathrm{~km}$ alrededor de él (Figura 11). Cuatro centrales hidroeléctricas utilizan las aguas fluviales y lacustres de la alta cuenca del Laja: Abanico (1948), El Toro (1973), Antuco (1981) y Rucúe (1998) (Mardones y Vargas 2005) ${ }^{4}$. La mayor de estas centrales es El Toro, la que establece una fuerte influencia en las variaciones de volumen y nivel del lago, por lo que en estudios anteriores se afirma que a medida que aumenta la producción de energía en esta central hidroeléctrica [El Toro], el nivel del lago Laja disminuye (Mardones y Vargas 2005:97).

El uso del agua aquí ha llegado a ser particularmente competitivo entre los actores involucrados originándose severas crisis del recurso hídrico particularmente en los años con déficit pluviométrico, ya que se sobreexige al lago para lograr abastecer a 


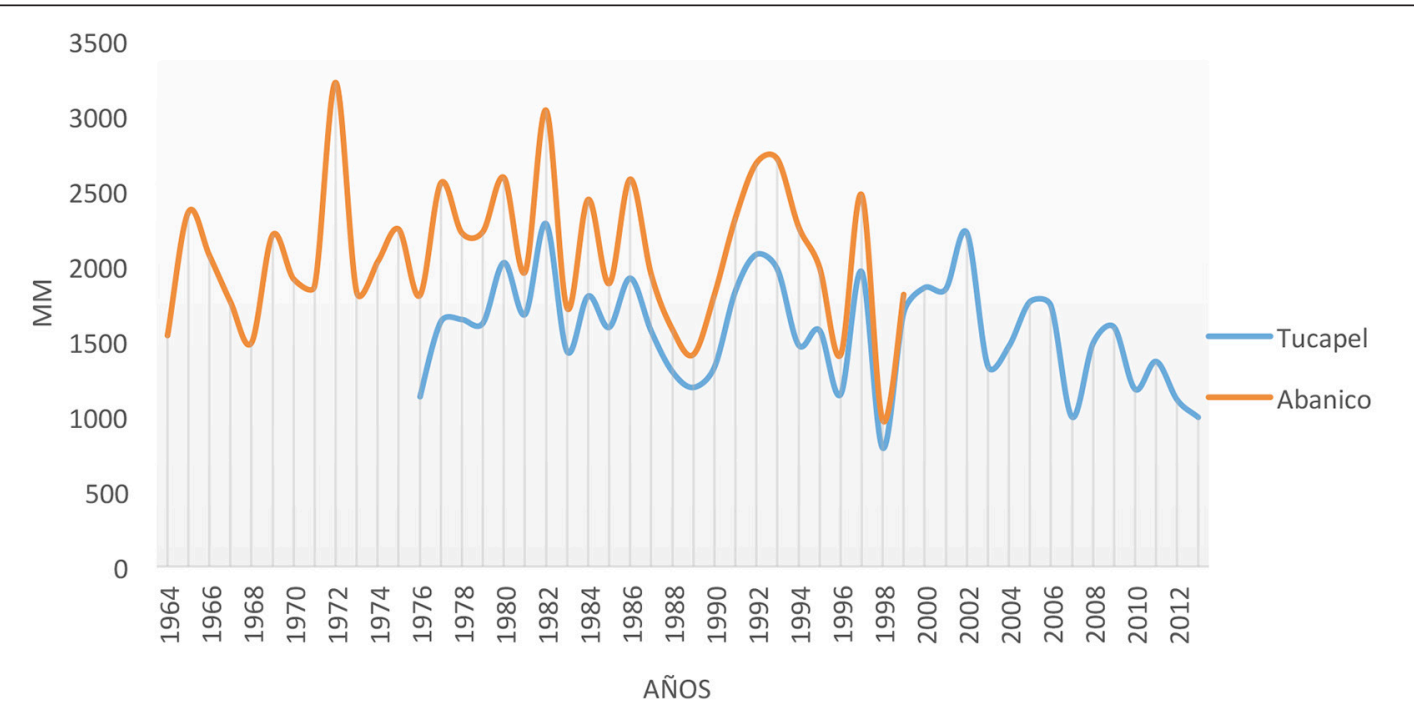

Figura 10. Precipitaciones anuales promedio (mm) para las estaciones Abanico y Tucapel (1960-2005). Fuente: Elaboración propia en base a datos DGA.

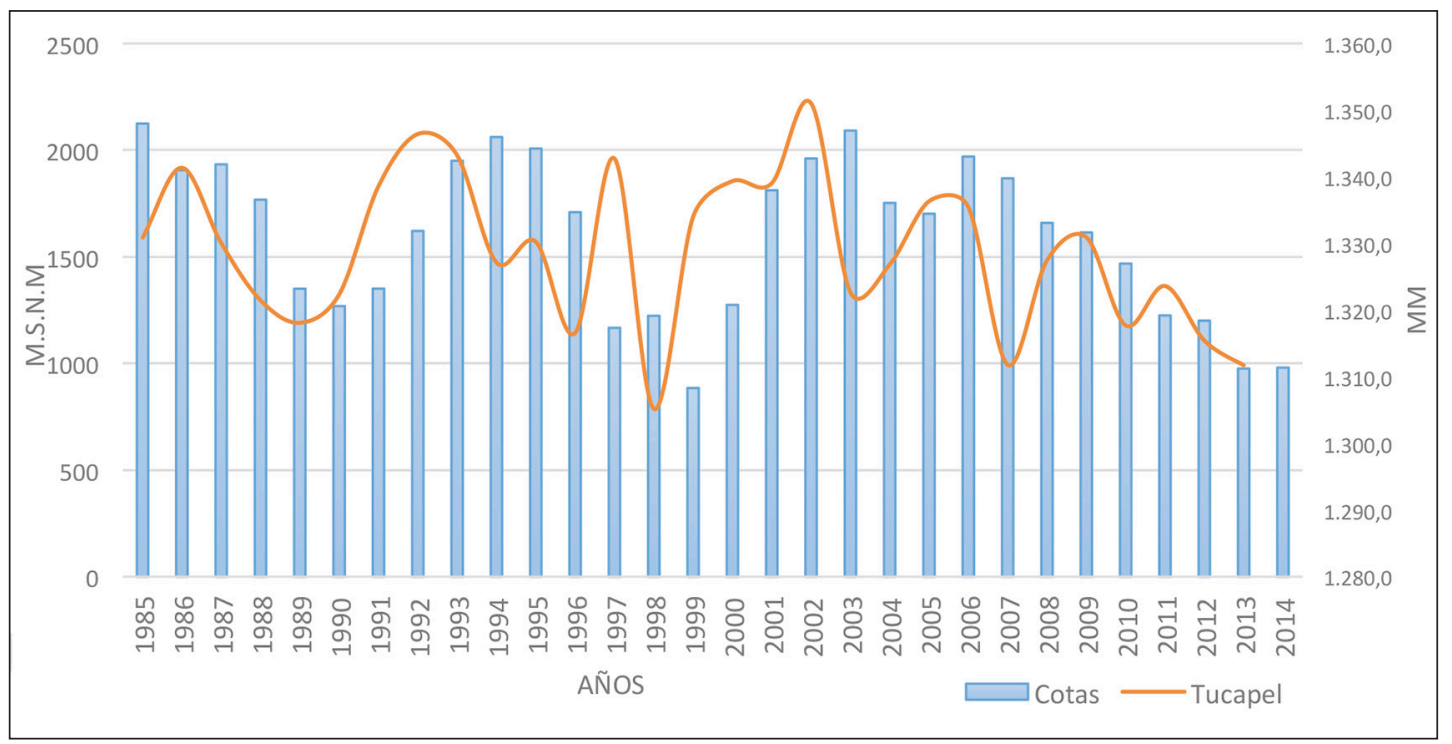

Figura 11. Comparación entre las precipitaciones $(\mathrm{mm})$ de la estación meteorológica Tucapel y las cotas (m.s.n.m.) que presenta el espejo de agua (1985-2013). Fuente: Elaboración propia.

estos dueños de los derechos de agua en la misma cantidad de $\mathrm{m}^{3}$ que utilizarían en un año normal (Rozas 1999).

El Instituto Nacional de Derechos Humanos (INDH) destaca dentro de su Mapa de Conflictos Socioambientales (2015) el conflicto del lago Laja. La Agrupación Canalistas de Laja y la Asociación de Canalistas del Laja responsabilizaron a la empresa
Endesa por un uso indiscriminado del recurso hídrico en las centrales, a pesar de estar normada la utilización de este elemento en un convenio suscrito en 1958 entre la Dirección de Obras Hidráulicas (DOH) y la empresa. Durante noviembre del 2013 Endesa optó por judicializar la disputa, haciendo ingreso al Primer Juzgado de Letras de Los Ángeles una solicitud de Junta de Vigilancia para establecer 


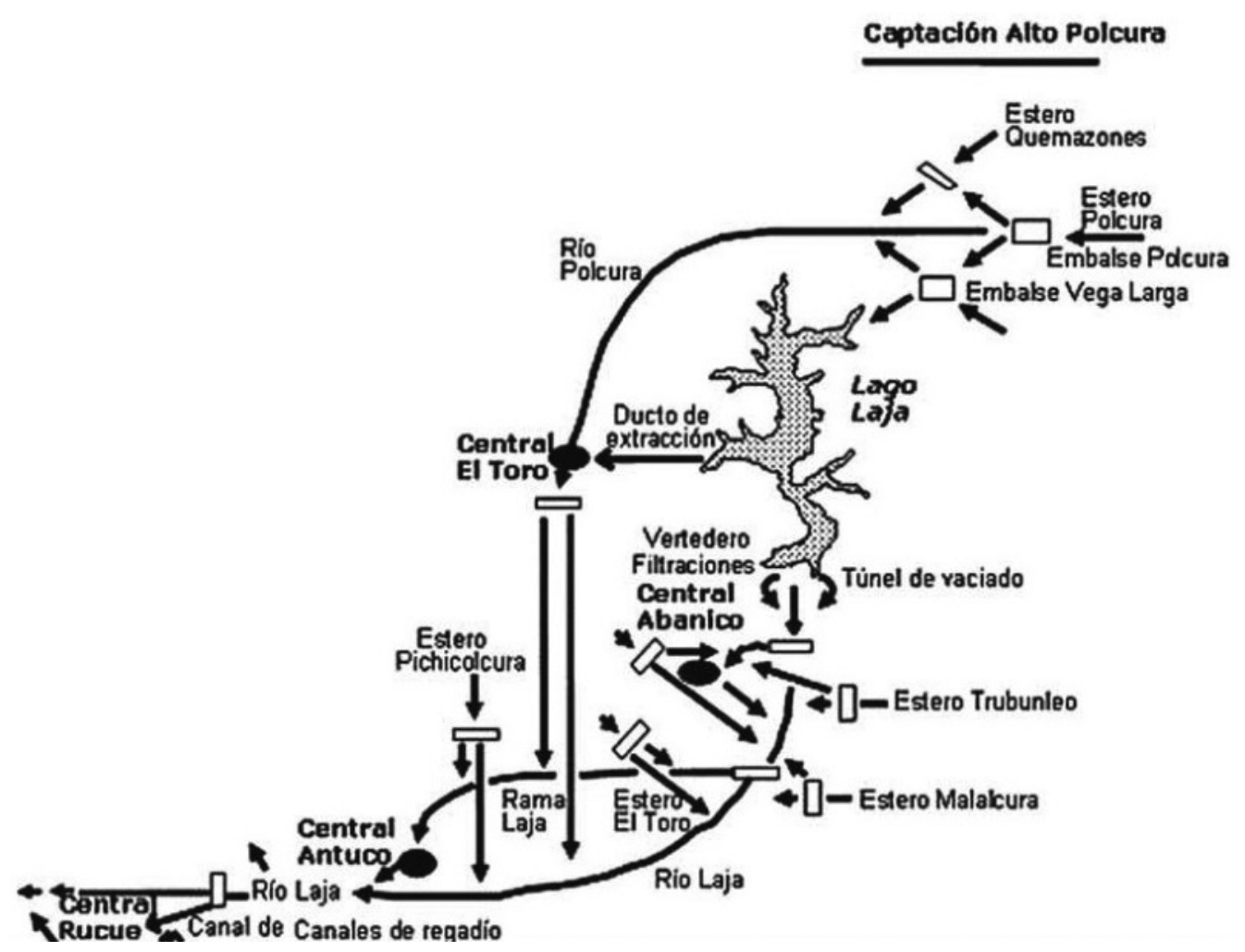

Figura 12. Manejo Hidrológico lago Laja y afluentes. Fuente: Mardones y Vargas (2005).

y administrar los derechos de uso de cada una de las partes sin la inclusión del lago Laja ${ }^{5}$ (INDH 2015). Este acuerdo permitirá extraer $700 \mathrm{hm}^{3}$ fijos y 200 $\mathrm{hm}^{3}$ variables, dependiendo de las condiciones hidrológicas del lago.

\section{Conclusiones}

El lago Laja, ubicado en la región central de Chile ha sufrido variaciones significativas durante las últimas décadas (1985 a 2016). Presentándose crisis hídricas en 1999 y 2013, llegando en este último año a un nivel de drenaje de cuenca que alcanzó 5.100 ha de un total de 12.000 ha aproximadas. La tendencia de variaciones marca un descenso constante para el período 1986-1999 y 2009-2014, destacándose una de las mayores sequías registradas en el país que condujo a racionamientos eléctricos (septiembre de 1999).

Se estudiaron dos variables climáticas para contrastarlas con antrópicas y desestimar sus posibles efectos en el cuerpo de agua. La variable temperatura muestra el aumento sostenido entre
$1,3{ }^{\circ} \mathrm{C}$ y $1,6{ }^{\circ} \mathrm{C}$ para el periodo de $1965-2014$-a excepción de 1999 y 2008-. La segunda variable estudiada fueron las precipitaciones, marcando una tendencia descendente con niveles críticos en los años 1998 y 2013 (>1.000 mm) cuando la media anual histórica es cercana a los 1.500-2.000 mm. No se aprecia una disminución tal que pueda ser asociada exclusivamente a los factores climáticos -precipitaciones y temperatura- como causantes de la reducción del recurso hídrico en el lago.

La entrega de derechos de agua en la comuna de Antuco, donde se sitúa el lago Laja, corresponden al tipo superficial. Predominan los derechos declarados para producción hidroeléctrica y riego desde el año 2014. El 78\% de estos derechos no cuenta con un registro detallado del caudal utilizado ni de su procedencia, por lo que la fiscalización a los túneles de vaciado que surten a las centrales hidroeléctricas es uno de los primeros pasos, para así manejar sosteniblemente este cuerpo de agua.

La reducción del recurso hídrico almacenado en el cuerpo de agua del Laja es de gran relevancia para toda la cuenca, especialmente por: 
a) La pérdida del turismo local, pesca, ecoturismo y turismo aventura en el Salto del Laja, localizado a $110 \mathrm{~km}$ río abajo, que están compuestos por cuatro espectaculares cascadas de entre 20 a $35 \mathrm{~m}$ de altura, que actualmente no están protegidos o resguardados de la escasez hídrica.

d) Escasez hídrica (agua de pozos, napas subterráneas y vertientes) para los habitantes, los pequeños y medianos agricultores -agrupados en más de veinte asociaciones de canalistasy para el funcionamiento de la misma planta hidroeléctrica que está en la cabera de la cuenca. e) Aceleración de la desertificación en la zona. Pérdida de la calidad del suelo agrícola de la zona media de la cuenca y su transformación en otros usos no sostenibles: urbanización, plantaciones forestales, vertederos, industrias contaminantes.

\section{Agradecimientos}

Los autores agradecen por el financiamiento al proyecto DIUC 208.603.007-1. Fluctuaciones volumétricas de los glaciares de la Sierra Velluda ( $37^{\circ} 27^{\prime} \mathrm{S}$ y $71^{\circ} 24^{\prime} \mathrm{W}$ ) en las últimas décadas y sus consecuencias en el paisaje natural del Parque Nacional Laguna del Laja.

\section{Referencias Citadas}

Astorga, E.; Carrillo, F.; Folchi, M.; García, M.; Grez, B.; McPhee, B.; Sepúlveda, C.; Stein, H.

2015 Evaluación de los conflictos socioambientales de proyectos de gran tamaño con foco en agua y energía para el período 1998-2015. Consejo Nacional de Innovación para el Desarrollo (CNID), Santiago de Chile.

Bauer, C. J.

2009 Dams and markets: Rivers and electric power in Chile. Natural Resources Journal, 583-651.

Bauer, C. J.

2002 Contra la corriente: privatización, mercados de agua y el Estado en Chile. Lom Ediciones, Santiago.

Blanco Vergara A.

2010 Diagnóstico de problemas en la gestión de recursos hídricos: aspectos institucionales para una futura propuesta de modificaciones legales, reglamentarias y/o de prácticas administrativas.

Biblioteca del Congreso Nacional (BCN).

1999 Decreto 287. Decreta racionamiento en el sistema interconectado central (SIC) por el periodo que indica; dispone medidas para el manejo y superación del déficit y fija el valor del kilowatt/hora de déficit para dicho periodo. http://www.leychile.cl/Navegar?idNorma=137602

Becerra Pérez, M.; Sáinz Santamaría, J.; Muñoz Piña, C.

2006 Los conflictos por agua en México. Diagnóstico y análisis. Gestión y Política Pública XV: 111-143. http:// www.redalyc.org/articulo.oa?id=13315104

Boone, R.B.; Lackett, J.M.; Galvin, K.A.; Ojima, D.S.; Tucker, C.J.III.

2007 Links and broken chains: Evidence of human-caused changes in land cover in remotely sensed images. Environmental Policy 10:135-149. doi:10.1016/j.envsci.2006.09.006

Bustos, B.; Prieto, M.; Barton, J. (Editores).

2015 Ecología Política en Chile: poder, naturaleza, conocimiento. Editorial Universitaria, Santiago.

Budds, J.

2012 La demanda, evaluación y asignación del agua en el contexto de escasez: un análisis del ciclo hidrosocial del valle del río La Ligua, Chile. Revista de Geografía Norte Grande (52): 167-184.
Cabello Cádiz, P.; Torres, R.

2015 Conflictos socioambientales y acción colectiva de jóvenes de la región de Los Lagos (Chile). Revista Colombiana de Ciencias Sociales, 6(2): 253-277.

Centro de Despacho Económico de Carga del Sistema Eléctrico Interconectado Central (CDEC-SIC).

2014 Informe de estado de cotas y niveles de embalses y Lagunas: Sistema Interconectado Central. Publicaciones del CDEC-SIC, Santiago.

CEPAL.

2012 Disponibilidad futura de los recursos hídricos frente a escenarios de cambio climático en Chile. Serie medio Ambiente y Desarrollo 149. CEPAL, Santiago. Disponible en: http://repositorio.cepal.org/bitstream/handle/11362/5691/1/ S2013149_es.pdf

Chuvieco, E.

1998 Fundamentos de la Teledetección Espacial. Ediciones Rialp, España.

Díaz, C., Galetovic, A., Soto, R.

2000 La crisis eléctrica de 1998-1999: causas, consecuencias y lecciones. Centro de Economía Aplicada, Universidad de Chile.

Dirección General de Aguas (DGA)

2014a Informe sobre derechos de Agua concedidos y solicitados. DGA Publicaciones, Santiago.

DGA.

2014b Informe de temperaturas estación Digüillín 1965-2014. DGA. DGA Publicaciones, Santiago.

2014c Informe de temperaturas estación Caracol 1985-2014. DGA. DGA Publicaciones, Santiago.

2014d Informe de Precipitaciones estación Tucapel 19762014. DGA Publicaciones, Santiago.

Galleguillos, X.; Ojeda Leal, C.

2016 El paisaje en animación suspendida y su valoración como dinamizador del desarrollo rural de la comuna de Maullín. Revista de Geografía Norte Grande 65: 215-231. García, J.C.

2011 El Mosaico de las regiones de Montaña. Editorial Universidad de Cantabria, España. 
García, S.; Guerrero, M.

2006 Indicadores de sustentabilidad ambiental en la gestión de espacios verdes: Parque urbano Monte Calvario, Tandil, Argentina. Revista de Geografía Norte Grande 35:45-57. http://dx.doi.org/10.4067/S0718-34022006000100004

Gleick, P.H.

1998 Water in Crisis: Paths to Sustainable Water Use. Ecological Applications 8(3): 571-579. DOI: 10.1890/1051-0761(1998)008[0571:WICPTS]2.0.CO;2

Gleick, P.H.

1995 Amarga Agua Dulce: Los Conflictos por los Recursos Hídricos. Ecología Política 8:85-106.

González, L.; González, A.; Mardones, M.

2003 Evaluación de la vulnerabilidad natural del acuífero freático en la cuenca del río Laja, centro-sur de Chile. Revista Geológica de Chile 30(1):03-22. https://dx.doi. org/10.4067/S0716-02082003000100001

Instituto Nacional de Derechos Humanos (INDH).

2012 Mapa de Conflictos Socioambientales en Chile. Versión 2012. INDH, Santiago.

Instituto Nacional de Derechos Humanos (INDH).

2015 Mapa de Conflictos Socioambientales en Chile. Versión 2015. INDH, Santiago.

Krishnaswamy, J.; Bawa, K.; Ganeshaiah, K.N.; Kiran, M.C. 2009 Quantifying and mapping biodiversity and ecosystem services: Utility of a multi-season NDVI based Mahalanobis distance surrogate. Rem. Sens. Environ. 113(4):857-867. doi:10.1016/j.rse.2008.12.011

Larraín, S.

2006 El agua en Chile: entre los derechos humanos y las reglas del mercado. Polis, Revista Latinoamericana 14:112. http://polis.revues.org/5091

Larraín, S.; Poo, P.

2010 Conflictos por el agua en Chile. Entre los Derechos Humanos y las Reglas de Mercado. Ediciones B, Santiago.

Mardones, M.; Vargas, J.

2005 Efectos hidrológicos de los usos eléctrico y agrícola en la cuenca del río Laja. Revista de Geografía Norte Grande 33:89-102.

Mardones, M.; Jaque, E.

1991 Geomorfología del Alto Valle del Laja. En Anales del Primer Congreso de Ciencias de la Tierra. Instituto Geográfico Militar (IGM), Santiago.

Martínez, M. F.; Osnaya, P.

2004 Cambio climático: una visión desde México. Instituto Nacional de Ecología, México D.F.

Martínez-Alier, J.

2004 Los Conflictos Ecológico-Distributivos y los Indicadores de Sustentabilidad. Revista Iberoamericana de Economía Ecológica. 1:21-30. http://www.raco.cat/index.php/Revibec/ article/view/38278

Martínez del Castillo, E.; Serrano-Notivoli, R.; Novak, K.;

Longares, L.A.; Arrechea, E.; De Luis, M.; Saz, M.

2010 Cuantificación de los gradientes climáticos altitudinales en la vertiente norte del macizo del Moncayo a partir de una nueva red de estaciones automáticas en altura. Actas $8^{\circ}$ Congreso internacional de la Asociación Española de Climatología. Cambio Climático. Extremos e impactos. http://aeclim.org/wp-content/uploads/2016/02/0050_PUSA-VIII-2012-E_MARTINEZ.pdf
Maselli, F.

2004 Monitoring forest conditions in a protected Mediterranean coastal area by the analysis of multiyear NDVI data. Rem. Sens. Environ. 89:423-433. doi:10.1016/j.rse.2003.10.020

Ministerio del Medio Ambiente (MMA).

2014 Plan de adaptación al Cambio Climático. Oficina de Cambio Climático, Santiago.

Ministerio de Obras Públicas (MOP).

2011 Estrategia Nacional de Manejo Recursos Hídricos 2012-2025. MOP, Santiago. Disponible en: http://www. mop.cl/Documents/ENRH_2013_OK.pdf

Niemeyer, H.; Cereceda, P.

1984 Hidrografía y Geografía de Chile. Tomo VIII. Instituto Geográfico Militar, Santiago.

Obregón, C.E.

2013 El agua y los territorios hídricos en la Región Metropolitana de Santiago de Chile. Casos de estudio: Tiltil, Valle de Mallarauco y San Pedro de Melipilla. Estudios Geográficos 74(274): 255-285.

ONU.

2014 Agua y Energía. Informe de las Naciones Unidas sobre el desarrollo de los recursos hídricos en el mundo. UNESCO, Italia. Obtenido desde: http://unesdoc.unesco. org/images/0022/002269/226962S.pdf

Peña, $\mathrm{H}$.

2004 Chile: 20 años del Código de Aguas. Mercados (de derechos) de agua: experiencias y propuestas en América del Sur. CEPAL, Santiago.

Postigo, J.C. (Ed.)

2013 Cambio Climático, Movimientos Sociales y Políticas Públicas. Una vinculación necesaria. Consejo Latinoamericano de Ciencias Sociales (CLACSO) Instituto de Ciencias Alejandro Lipschutz (ICAL), Santiago de Chile.

Prieto, $\mathrm{M}$.

2017 El Riego que el Mercado no Quiere Ver: Historia del Despojo Hídrico en las Comunidades de Lasana y Chiu-Chiu (Desierto de Atacama, Chile). Journal of Latin American Geography, 16(2): 69-91.

Prieto, M.; Bauer, C.

2012 Hydroelectric power generation in Chile: An institutional critique of the neutrality of market mechanisms. Water international, 37(2): 131-146.

Restrepo, JD; Kettnerb, AJ; Syvitski, JPM.

2015 Recent deforestation causes rapid increase in river sediment load in the Colombian Andes. Anthropocene. 10:13-28. http://dx.doi.org/10.1016/j.ancene.2015.09.001

Rozas, $\mathrm{P}$

1999 La crisis eléctrica en Chile: antecedentes para una evaluación de la institucionalidad regulatoria. CEPAL, Santiago. URL: http://repositorio.cepal.org/handle/11362/6402

Saavedra Brofman, M.

2008 Código de aguas chileno y reforma 2005.

Seoane, J.; Taddei, E.; Algranati, C.

2006 Las nuevas configuraciones de los movimientos populares en América Latina. En Boron, A.A.; Lechini, G. (eds.) Política y movimientos sociales en un mundo hegemónico. Lecciones desde África, Asia y América Latina. CLACSO, Buenos Aires. Disponible en: http://bibliotecavirtual.clacso. org.ar/ar/libros/sursur/politica/PIIICuno.pdf 
Servicio Nacional de Geología y Minería (SERNAGEOMIN); Niemeyer, H.; Muñoz, J.

1983 Hoja Laguna de La Laja, Región de Biobío. Carta Geológica de Chile 1:250.000. Publicaciones del Servicio Nacional de Geología y Minería, Santiago.

Speranza, J.; Bonhomme, G.; Bonilla Martínez, O.A.

2013 Pobreza, ambiente y cambio climático. Colección. CLACSO (ed.), Buenos Aires: CLACSO. Disponible en: http://bibliotecavirtual.clacso.org.ar/clacso/clacso-crop/20130315113626/ PobrezaAmbi enteyCambioClimatico.pdf

Syvitski, J.P.M.

2003 Supply and flux of sediment along hydrological pathways: research for the 21 st century. Glob. Planet. Change. 39(1-2):1-11.
Tovar, C.M.

2012 El índice normalizado diferencial de la vegetación como indicador de la degradación del bosque. Unasylva: Revista internacional de silvicultura e industrias forestales. 238(68):39-46.

Pineda, M.C.; Martínez-Casasnovas, J.A.; Viloria, J.

2016 Relación entre los cambios de cobertura vegetal y la ocurrencia de deslizamientos de tierra en la serranía del interior de Venezuela. Interciencia 41:190-197.

Yáñez, N.; Molina, R.

2011 Las aguas indígenas en Chile. LOM Ediciones, Santiago. Zorrilla, J.J.

2000 Enciclopedia de la Montaña. Ediciones Desnivel, Barcelona.

\section{Notas}

1 A mediados del siglo XIX sería la fecha de corte del Holoceno, y luego de esto comenzaría el Antropoceno.

2 Esta información es pública y se puede encontrar en la página web http://snia.dga.cl/BNAConsultas/reportes

3 Ver Guía de Análisis del Sistema de Cuencas Hidrográficas (SUBDERE 2013), el Plan Nacional de Adaptación al Cambio Climático Chile (MMA 2014) y la Estrategia
Nacional de Manejo Recursos Hídricos 2012-2025 (MOP 2011).

4 Para más detalles ver la Resolución de Calificación Ambiental RCA para la operación de la central hidroeléctrica en este caso. 5 http://www.angelino.cl/2015/12/14/ministros-de-obraspublicas-energia-y-agricultura-junto-a-endesa-y-regantesfirman-convenio-para-mejor-uso-de-aguas-del-lago-laja/ 